The International Journal of Indian Psychology: Volume: 01 | Issue: 04 | ISSN 2348-5396

\title{
Correlation between Personality Types and Color Shade Preference
}

\author{
Divya Ghorawat*, Ravina Madan**
}

\begin{abstract}
ABSTSRACT:
The main aim of this study was to find out whether the colour shade preferences of individuals, grouped according to their personality types are alike or not. The researchers also tried to study the difference in colour shade preferences based on gender differences. The objective was to understand whether the colour shade preferences of individuals are affected by their individual personality types or not and whether gender plays any role in selection of colour shades of individuals. The study sample consisted of a total of 80 subjects, randomly selected from within the age group of 18-25. An attempt was made to maintain a balance between two genders and across the ages. The research instruments used were Eysenck's Personality Test (to measure the personality types) and a separate Colour Bar- Colour Preference Test was designed to serve the purpose of this study. The subjects were made to fill both the questionnaires and then the items were scored and results were analyzed. Positive scoring was done for Eysenck's personality questionnaire and negative scoring was used to score the Colour Bar-Colour Preference Test. The data collected was divided into: Introverts (female, male) and Extroverts (female, male). From the data collected the mean, standard deviation and correlation between extraversion scores and the most preferred colour scores, for all the four groups. The mean, standard deviation, and correlation for the four groups was found to be 436.4 (IF), 529.2 (IM), 504 (EF), 453.4 (EM); 5.47 (IF), 6.52 (IM), 5.48 (EF), 6.93(EM); -0.3 (IF), -0.1 (IM), 0.1 (EF) and 0.5 (EM) respectively. From this the conclusion was drawn that there was no significant correlation found between the personality types and colour shade preferences of the subjects except in the case of extroverted males.

Recommendations: Increase the sample size as that proved to be a limitation to this study. A study across ages is also possible and might give different results.
\end{abstract}

KEY WORDS: Colour, Personality, Correlation, Colour Bar- Colour Preference Test.

\section{INTRODUCTION}

Various studies have been conducted across the globe to understand and establish a correlation between colour shade preferences and difference in personality types. The results of majority of the studies show that colour shade preference is significantly affected by the personality types of individuals. The aim of this study is to reconfirm and re-establish the correlations between the variables.

As per a recent study conducted by Dunja Cijic and Vojislava Bujarski, in 2010, it is evident that there exists a clear distinction in the colour shades preferred by different personalities. As a result of the study it was seen that social introverts preferred darker, duller shades while the extroverts were seen to prefer brighter shades.

*\&** Researcher, Pandit Deendayal Petroleum University. Ahmedabad, Gujarat 


\section{The International Journal of Indian Psychology: Volume: 01 | Issue: 04 | ISSN 2348-5396}

Another thesis presented to the faculty of the department of psychology at Emporia Kansas State College by Stephen DeWith Smith, 1976, also attempts to study the relationships between the colour preferences and personality traits of humans. Using Edward's Personal Preference Schedule (1959 edition) - for personality and Luscher Colour Test (short form): the four primary colours- for colour preference, it was concluded that a significant amount of positive correlation between the colour preference and personality traits was there.

Thus the main objective of this study is to find out whether or not an individual's colour shade preference is affected by his personality type and whether the selection of colours is affected by genders.

H0: there might or might not be a correlation between the personality types and colour preferences of the subjects.

H1: the extroverts will prefer brighter shades while the introverts will go for duller shades.

Personality

Gordon W. Allport defines personality as "a dynamic organization within the individual of those psychological systems that determine his unique adjustment to his environment."

In this definition, Allport tries to explain the dynamic nature and organizational aspects of personality and emphasizes on its role in the way an individual adjusts with his environment or surroundings. However this definition is not complete in the sense that it holds personality as an aspect within the individual and not as being integrated with it.

Personality, as defined by Eysenck, is "the more or less stable and enduring organization of a person's character, temperament, intellect and physique, which determine his unique adjustment to the environment." This definition is more or less complete as it tries to provide a physiological base to personality and hence attempts to give a balanced consideration to the role of both nature and nurture in shaping one's personality. This definition also attempts to make personality somewhat measurable and assessable, hence giving it a scientific base.

Hence it can be said that personality is "a blend of constantly evolving and changing pattern of one's unique behavior, emerged as a result of one's interactions with one's environment and directed towards some specific ends."

Colours and Colour Preference

Colour is a sensation (of sight) produced as a result of electromagnetic waves hitting the retina of the eye. These waves are the ones that are reflected by various objects in the environment. Colour preference on the other hand can be defined as the tendency of an individual or a group to favour a particular colour or colours over others.

A Psychometric test includes a wide array of evaluation tools that measure one's knowledge, abilities and personality. It is a measurement instrument that consists of a sample of behavior obtained under standardized conditions and evaluated using established scoring rules.

Correlation can be defined as a mutual and reciprocal relationship between two or more variables.

A lot of studies have been conducted using the two variables that are a part of this study.

K. Warner Schaie, West Virginia University, in 1960, studied the relation between color and personality. Models where used which conceptualize response to colour as a means for studying emotional behavior. Instruments used were Rorschach test (to assess personality traits) and luscher test (to asses colour preferences) for his research. It was noticed that a particular personality type people respond to or prefer some particular colour.

A paper on Colour and Personality, using Strong's Interest inventory and Cattell's 16 PF Questionnaire was presented at Rense Lange, Sigmund Testing, Dallas, TX, by Jason Rentfrow, 


\section{The International Journal of Indian Psychology: Volume: 01 | Issue: 04 | ISSN 2348-5396}

University of Cambridge, UK.The researcher here studied whether the preferences of colour one had were in any way affected by the kind of personality trait he possessed. He made use of the following three instruments:

- Strong's Interest Inventory- for colour preference

- Cattell's 16 PF- for personality.

- Dewey Colour System Test was also used.

The conclusions of the research clearly reinforce the notion that the colour preferences are valid indicators of an individual's personality traits.

Lauren Hartsfield conducted a research on the effect of colour on personality traits in 2008, to be presented at Robert Morris University, Moon Township, PA. He used Big Five Personality Test on one of two different colours of paper (red or blue). Although it was expected that red would increase extraversion scores and blue would decrease them, results showed no differences between the groups.

\section{METHODOLOGY}

For the purpose of this study the target audience selected was between the age group of 18-25. A sample of 80 college students (39 females and 41males) was randomly chosen from Ahmedabad city. The researchers used two questionnaires namely, Eysenks personality test and a self prepared colour bar: colour preference questionnaire. Each subject was required to fill both these questionnaires one after the other.

Eysenks personality test, developed by Hans Eysenk and his wife Sybil Eysenk, is a questionnaire devised to assess the personality traits of a person. The reliability of the questionnaire was found to be 0.7 . This questionnaire measured personality on three dimensions, which were extraversion, psychotism and neuroticism. The researcher focused on only one dimension in this study which was extraversion. This questionnaire consisted of 36 questions and had a scale ranging from very inaccurate to very accurate. The subject was required to read the question and choose the most appropriate option. The other questionnaire used was a self prepared questionnaire that measures the colour preferences of the subjects. This questionnaire consisted of a colour bar showing 5 shades of 8 colours. The subject was required to rank the shade of each colour from 1 to 5 according to his preference. This questionnaire had negative scoring which means that when a subject gives $1^{\text {st }}$ rank to a particular shade then that shade gets a score of 5.There was no time limit for both the questionnaires.

After the data was collected the sample was divided into 4 groups, based on the gender and personality type of the subjects. Group1: introvert females group 2: introvert males, group 3: extrovert females, group 4: extrovert males. Then the mean, standard deviation and correlation was calculated. The mean and S.D. was calculated for the scores of shades of all the colours for all the groups and the correlation was calculated using the extraversion scores and the scores for the most preferred colour for each participant. 
The International Journal of Indian Psychology: Volume: 01 | Issue: 04 | ISSN 2348-5396

RESULTS AND DISCUSSIONS

DATA TABLE:

TABLE NO.1

\begin{tabular}{|l|l|l|l|}
\hline GROUPS & MEAN & $\begin{array}{l}\text { CORRELATION } \\
\text { COEFFICIENT }\end{array}$ & $\begin{array}{l}\text { STANDARD } \\
\text { DEVIATION }\end{array}$ \\
\hline INTROVERT(F) & 436.4 & -0.1 & 6.52 \\
\hline INTROVERT(M) & 529.2 & -0.3 & 5.74 \\
\hline EXTROVERT(F) & 504 & 0.1 & 5.48 \\
\hline EXTROVERT(M) & 453.4 & 0.5 & 6.93 \\
\hline
\end{tabular}

Discussions: Referring to the above data table we can see that no significant difference was found in the results, except for extrovert males' correlation coefficient.

\section{CONCLUSION}

From this study we can conclude that the hypothesis made by the researcher was rejected since no significant correlation was found between the personality type of the subject and his colour preference, but it was also seen that this age group overall prefers brighter colours as compared to dull shades. The sample group consists of college going students who are highly affected by the latest trends of fashion. Since bright colours are in fashion presently we can probably conclude by saying that colour preferences of the people does not depend entirely on the personality type but instead to a great extent depends on the latest trends of fashion.

\section{RECOMMENDATIONS AND LIMITATIONS}

There were various limitations found to this study. Firstly, colour preference is subjective and can change easily. Secondly, introversion and extroversion is very situational and has a very thin line between them. Many times the answers given by the subjects for the personality test are highly dependent on the moods of the subject at that particular time. Also people tend to give answers which are socially accepted (self serving bias) instead of their actual answers which hinders the study. The sample size taken for this study was 80 . This probably could have been a limitation for our study since the sample size was too small to represent the population.

\section{APPENDIX}

EYSENCK'S PERSONALITY INVENTORY

NAME:

AGE:

SEX:

INSTRUCTIONS: Given below is an online version of Eysenck's Personality Inventory. Read the given statements carefully and select one option that is most appropriate in your case, on a general basis. The inventory is based on careful introspection and your knowledge about self. You are hence required to answer as truthfully as possible.

1) I enjoy meeting new people.

$\begin{array}{llllllll}\text { Very } & C & \mathrm{C} & \mathrm{C} & \mathrm{C} & \mathrm{C} & \begin{array}{l}\text { Very } \\ \text { Accurate }\end{array}\end{array}$
(C) 2014 www.ijip.in
July-September 2014
73 | P a g e 
The International Journal of Indian Psychology: Volume: 01 | Issue: 04 | ISSN 2348-5396

2) I frequently worry.

Very

Inaccurate

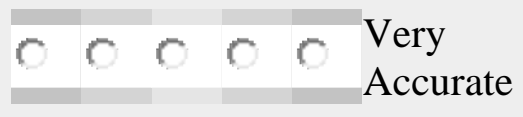

3) I am at ease around others.

Very

Inaccurate

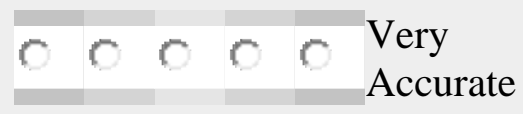

4) I respect authority.

Very

Inaccurate

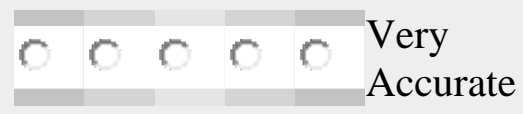

5) I know how to get people to have fun.

Very

Inaccurate

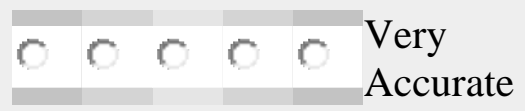

6) I frequently feel frustrated.

Very

Inaccurate

$$
\circ \circ \circ \circ \begin{aligned}
& \text { Very } \\
& \text { Accurate }
\end{aligned}
$$

7) I would rather play by the rules.

Very

$$
\text { C } \odot \circ \circ \begin{aligned}
& \text { Very } \\
& \text { Accurate }
\end{aligned}
$$

Inaccurate

8) I enjoy social gatherings.

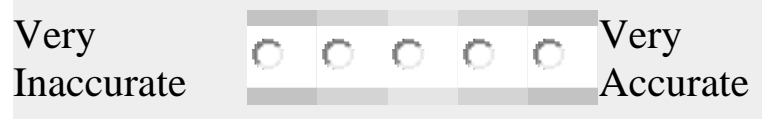

9) I make friends easily.

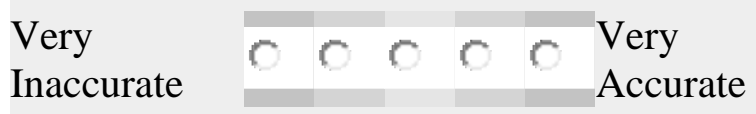

10) I have no trouble approaching people.

Very

Inaccurate

$$
\odot \circ \odot \circ \quad \begin{aligned}
& \text { Very } \\
& \text { Accurate }
\end{aligned}
$$


The International Journal of Indian Psychology: Volume: 01 | Issue: 04 | ISSN 2348-5396

11) I can be egocentric.

Very

Inaccurate

$$
\circ \quad 0 \quad 0 \quad \begin{aligned}
& \text { Very } \\
& \text { Accurate }
\end{aligned}
$$

12) I can be unsympathetic.

Very

Inaccurate

$$
\circ \quad 0 \quad 0 \quad \begin{aligned}
& \text { Very } \\
& \text { Accurate }
\end{aligned}
$$

13) I tend to be nervous.

Very

Inaccurate

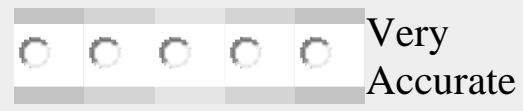

14) I like to be intimidating.

Very

Inaccurate

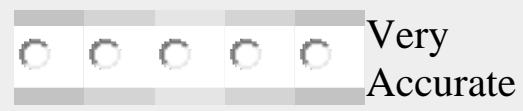

15) I am very energetic.

Very

Inaccurate

$$
0000 \begin{aligned}
& \text { Very } \\
& \text { Accurate }
\end{aligned}
$$

16) I often feel lonely.

Very

$$
\circ 0000 \begin{aligned}
& \text { Very } \\
& \text { Accurate }
\end{aligned}
$$

Inaccurate

17) I like being in high energy environments.

Very

$$
\circ \quad 0 \quad 0 \quad \begin{aligned}
& \text { Very } \\
& \text { Accurate }
\end{aligned}
$$

Inaccurate

18) I tend to be more comfortable with the known than the unknown.

Very

$$
\circ .0 .0 \quad \begin{aligned}
& \text { Very } \\
& \text { Accurate }
\end{aligned}
$$

Inaccurate

19) I sometimes feel extremely sad for no reason.

Very

Inaccurate

$$
0.000 \begin{aligned}
& \text { Very } \\
& \text { Accurate }
\end{aligned}
$$


The International Journal of Indian Psychology: Volume: 01 | Issue: 04 | ISSN 2348-5396

20) I am hypersensitive.

Very

Inaccurate

$$
\circ .0 .0 \begin{aligned}
& \text { Very } \\
& \text { Accurate }
\end{aligned}
$$

21) I suffer from anxiety.

Very

Inaccurate

$$
\circ \quad 0 \quad 0 \quad 0 \begin{aligned}
& \text { Very } \\
& \text { Accurate }
\end{aligned}
$$

22) I am very talkative.

Very

Inaccurate

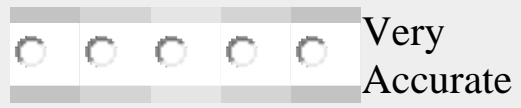

23) I am outgoing.

Very

Inaccurate

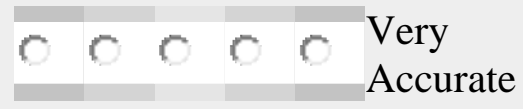

24) Being in debt would not worry me.

Very

Inaccurate

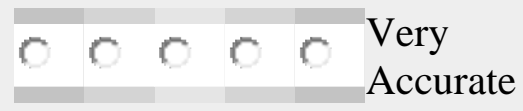

25) I am quiet around others.

Very

$$
\circ \quad 000 \begin{aligned}
& \text { Very } \\
& \text { Accurate }
\end{aligned}
$$

Inaccurate

26) I enjoy being part of a group.

Very

$$
\circ \circ 000 \begin{aligned}
& \text { Very } \\
& \text { Accurate }
\end{aligned}
$$

Inaccurate

27) I think people are overly cautious.

Very

$$
\circ .0 .0 \begin{aligned}
& \text { Very } \\
& \text { Accurate }
\end{aligned}
$$

Inaccurate

28) I behave properly.

Very

Inaccurate

$$
\circ .000 \begin{aligned}
& \text { Very } \\
& \text { Accurate }
\end{aligned}
$$


The International Journal of Indian Psychology: Volume: 01 | Issue: 04 | ISSN 2348-5396

29) I tend to brood on past mistakes.

Very

Inaccurate

$$
\circ \quad 0 \quad 0 \quad \begin{aligned}
& \text { Very } \\
& \text { Accurate }
\end{aligned}
$$

30) I am very tense.

Very

Inaccurate

$$
\circ .000 \begin{aligned}
& \text { Very } \\
& \text { Accurate }
\end{aligned}
$$

31) I prefer to go my own way than live by the rules.

Very

Inaccurate

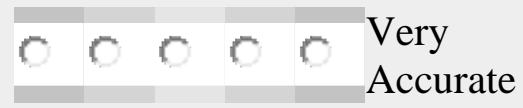

32) I fear for the worst.

Very

Inaccurate

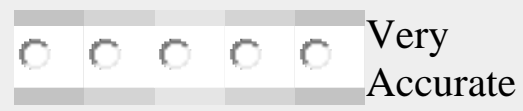

33) I frequently feel guilty.

Very

Inaccurate

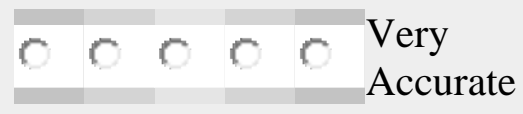

34) I try not to be rude to people.

Very

$$
\circ 000 \begin{aligned}
& \text { Very } \\
& \text { Accurate }
\end{aligned}
$$

Inaccurate

35) I am very moody.

Very

$$
\circ \quad 0 \quad 0 \quad 0 \begin{aligned}
& \text { Very } \\
& \text { Accurate }
\end{aligned}
$$

Inaccurate

36) I would like other people to be afraid of me.

Very

$$
\circ .0 \% \begin{aligned}
& \text { Very } \\
& \text { Accurate }
\end{aligned}
$$


The International Journal of Indian Psychology: Volume: 01 | Issue: 04 | ISSN 2348-5396

COLOUR BAR - COLOUR PREFERENCE TEST

YELLOW

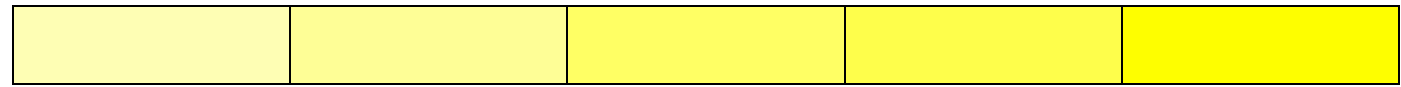

RED

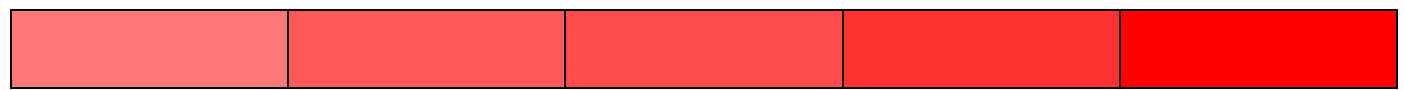

BLUE

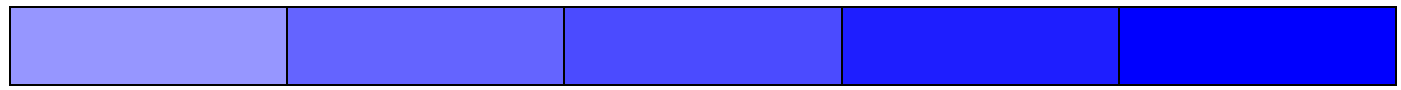

GREEN

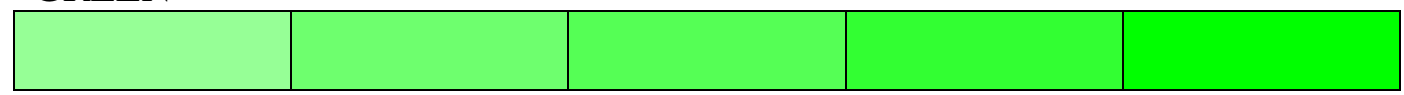

PURPLE

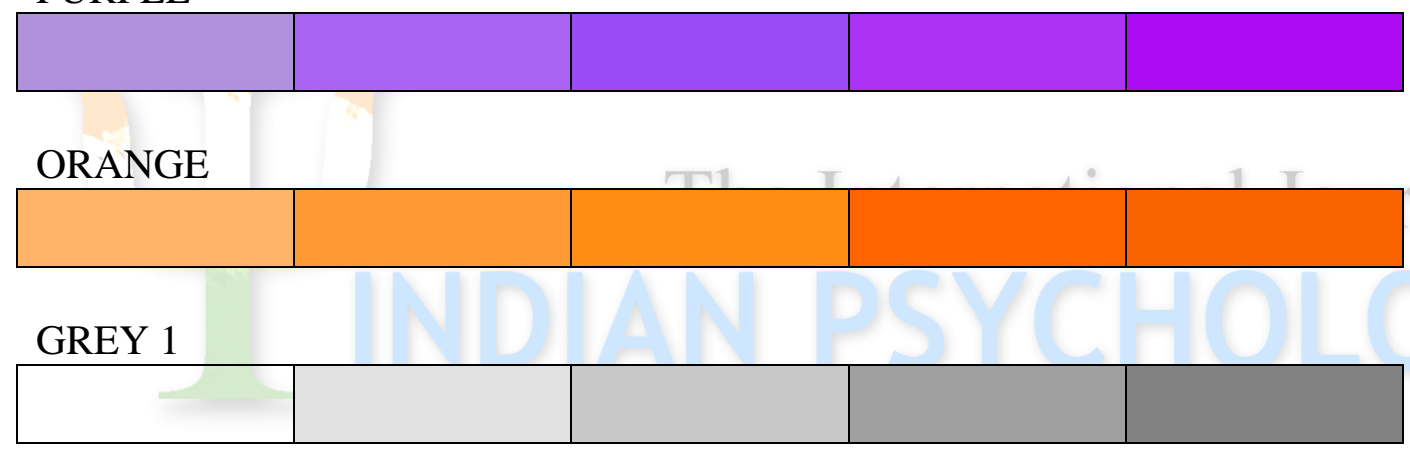

GREY 2

\section{COLOUR BAR- COLOUR PREFERENCE TEST}

(Scoring Grid)

INSTRUCTIONS: The following is the scoring grid of the Colour Bar- Colour Preference Test. You are required to refer to the Shade Card and fill in the Scoring Grid according to your preference of the shades of the given colour. To score, you may use the numbers 1,2,3,4,5; where 1 refers to the most preferred and 5 refers to the least preferred.

Note: please try to fill the grid by putting in 1 and 5 first, followed by the others.

\begin{tabular}{|l|l|l|l|l|l|}
\hline YELLOW & & & & & \\
\hline RED & & & & & \\
\hline BLUE & & & & & \\
\hline GREEN & & & & & \\
\hline PURPLE & & & & & \\
\hline
\end{tabular}

(C) 2014 www.ijip.in

July-September 2014

$78 \mid \mathrm{P}$ a g e 
The International Journal of Indian Psychology: Volume: 01 | Issue: 04 | ISSN 2348-5396

\begin{tabular}{|l|l|l|l|l|l|}
\hline ORANGE & & & & & \\
\hline GREY 1 & & & & & \\
\hline GREY 2 & & & & & \\
\hline
\end{tabular}

\section{REFERENCES}

1. http://deweycolorsystem.com/files/DCS_23.pdf

2. http://thesop.org/story/art/2006/12/06/the-effects-of-color-on-personality-andrelationships.php

3. http://weeklyworldnews.com/headlines/12653/favorite-color-reveals-personality-type/

4. http://www.drspeg.com/research/2008/personalitycolor.pdf

5. http://www.sknvibes.com/news/newsdetails.cfm/66176

6. http://www.uwpsychiatry.org/sls/relation\%20of\%20color\%20and\%20personality.schaie. 1966.pdf

7. https://esirc.emporia.edu/bitstream/handle/123456789/2495/Smith\%201976.pdf?sequenc $\mathrm{e}=1$

8. http://www.aktuelnosti.org/pdf/2010/2010[4]05.pdf http://similarminds.com/eysenck.html

9. Mangal, S.K., Advanced Educational Psychology, New Delhi: PHI Learning Pvt. Ltd., 2008.

10. Morgan, C.T., Introduction To Psychology, New York: McGraw-Hill, 1961.

11. http://medind.nic.in/icg/t09/i1/icgt09i1p27.pdf 